\title{
Fiestas Y Danzas NaCiOnales EN ORGaNIZACIONES DE MigRanTES Y EN ESCUELAS DE BUENOS AIRES-ARGENTINA. CONTINUIDADES Y QUIEBRES EN LA TRANSMISIÓN GENERACIONAL
}

\author{
Gabriela Novaro ${ }^{1}$ \\ Universidad de Buenos Aires, Argentina
}

\begin{abstract}
La reflexión que se realiza sobre las fiestas y las danzas se inserta en una investigación sobre migración y educación que hace años realizo con población procedente de Bolivia en Buenos Aires - Argentina. En mi trabajo atiendo especialmente a los procesos de transmisión intergeneracional de referencias de identificación en contextos comunitarios, familiares y escolares. Las fiestas ponen en relación distintas generaciones entre las que se expresan tensiones entre "seguir siendo" (boliviano) y seguir estando en Argentina. Registro esta situación en una localidad de la provincia de Buenos Aires con un alto componente de población procedente de Bolivia y sus descendientes. Realizo un contrapunto entre el despliegue de danzas bolivianas en las celebraciones comunitarias y en las fiestas de las escuelas de la localidad. En ellas advierto la vigencia de un fuerte mandato nacionalizador que obtura el trabajo con la condición transnacional de los niños y jóvenes del barrio.

Palabras claves: Fiestas, danzas, organizaciones de migrantes, escuelas, identificación nacional, transmisión generacional
\end{abstract}

\section{INTRODUCCIÓN}

En este trabajo reflexiono sobre el sentido de las fiestas y las danzas en contextos migratorios comunitarios y escolares, más concretamente, sobre la vinculación de las fiestas y las danzas nacionales con los procesos de transmisión de referencias de identificación a las nuevas generaciones.

1 Contacto: gabriela.novaro@gmail.com 
El trabajo se desarrolla en un barrio de Escobar, localidad ubicada $50 \mathrm{~km}$ al norte de la ciudad de Buenos Aires (Argentina). El barrio está habitado por un alto componente de población procedente de Bolivia y sus descendientes. Allí sostengo mi investigación desde el año 2010.

A lo largo del trabajo fui advirtiendo que las festividades representan un momento particularmente relevante de la vida colectiva, donde se pone en evidencia la pertenencia binacional de los adultos y sobre todo de las nuevas generaciones, las apuestas por inclusión en la sociedad argentina y también por mantener la distintividad como bolivianos. Me pregunto en este texto por las continuidades y los quiebres entre estos sentidos de las fiestas y los mandatos de identificación que se registran en las fiestas escolares de la localidad.

En Argentina las investigaciones sobre la problemática migratoria vienen desarrollándose hace años, centrando el interés en temáticas como la inserción en el mercado laboral y las políticas de poblamiento. Los procesos de identificación, la transmisión generacional y las prácticas expresivas no han recibido la misma atención. En este sentido intento realizar un aporte original a la temática desde una perspectiva antropológica.

E1 recorte propuesto me aproxima a problemáticas sumamente relevantes para un abordaje de los procesos migratorios: los sentimientos de afirmación comunitaria en las expresiones artísticas, la simultaneidad de múltiples pertenencias nacionales que visibilizan las fiestas y las danzas, las relaciones generacionales que se despliegan en ellas. En definitiva, lleva a reflexionar sobre los sentidos legitimados y la renovación de sentidos de prácticas expresivas fuertemente asociadas a la identificación colectiva.

En la localidad donde trabajo advierto que en situaciones comunitarias estas prácticas desbordan los significados estatales de la nacionalidad, muestran la preocupación de los adultos por la continuidad de las referencias en "sus descendientes" y expresan sentidos de identificación diferenciales en las distintas generaciones. Los contextos festivos escolares en Escobar dan cuenta tanto la renovación de los mandatos asimilacionistas tradicionales, como de los límites para incluir el carácter transnacional de gran parte de la población que habita las escuelas.

Es necesario considerar que la población boliviana es el segundo colectivo migrante en Argentina y que los niños bolivianos y descendientes de familias bolivianas representan un porcentaje significativo de la matricula escolar. En textos previos me he detenido en las formas de inclusión subordinada de estos niños. ${ }^{2}$ Me pregunto aquí si el lugar de "lo boliviano" en las fiestas nacionales argentinas también puede ser caracterizado desde la noción de inclusión subordinada. También me pregunto cómo poner esto en debate desde una propuesta amplia de inclusión que incluya apuestas por la interculturalidad y la igualdad educativa.

Estos interrogantes se despliegan en reflexiones localizadas en un barrio que muchos definirían como un espacio transnacional, marcado por pertenencias simultáneas a los territorios de origen y destino (Balibar; 2005; Haesbaert, 2013; Levitt \& Glick Schiller, 2004). En este contexto resultan evidentes las formas múltiples de identificación nacional y las experiencias ambivalentes de "vivir en las fronteras" (Bhabha 1998: 272), aunque el barrio se encuentra muy lejos de lo que los estados definen como líneas fronterizas.

2 Hemos registrado la presencia de los niños migrantes latinoamericanos en circuitos y escuelas devaluadas, la baja expectativa de su desempeño, el desconocimiento de sus trayectorias educativas previas, el silenciamiento de sus referencias de identificación (Novaro y Diez, 2011). 
Me detengo aquí en cómo las múltiples formas de relación con lo nacional se expresan en las festividades comunitarias y hacen de las mismas espacios para visibilizar relaciones hacia dentro y hacia fuera del colectivo migrante y para proyectar su continuidad en las nuevas generaciones. También para desafiar las proyecciones simples de integración que suelen caracterizar las instituciones escolares y se expresan en los eventos que las escuelas celebran.

\section{¿PORQUÉ LAS FIESTAS Y LAS DANZAS?}

Una aclaración necesaria para comenzar es que mi área de especialización es la antropología y la educación, y que inicialmente no me había propuesto atender particularmente a las fiestas y a las danzas. Sin embargo, no pude dejar de hacerlo al registrar la recurrencia con que año a año en la localidad se festejan el carnaval, el día de la independencia boliviana, las fiestas patronales, los aniversarios de las localidades de Bolivia de donde proviene al población. En todos estos eventos las danzas tienen un lugar destacado.

Advertí también que las fiestas son uno de los pocos espacios escolares donde "se invita" a las familias; por otra parte, me estimuló el hecho de que en los últimos años en el sistema educativo se han venido sucediendo intentos de flexibilizar el estilo protocolar y el mandato nacionalizador de las festividades y enriquecer la enseñanza de las danzas folclóricas.

Fui identificando algunos ejes de discusión que me resultan muy sugerentes para pensar las fiestas comunitarias y las fiestas escolares.

Las situaciones registradas hacen pertinente considerar y debatir el énfasis que algunos especialistas en el tema ponen en la distinción entre las celebraciones populares y las oficiales a partir de la clásica caracterización de Bajtin de los festejos carnavalescos (Bajtin, 2003).

Me interesó además cómo nuevas aproximaciones al estudio socioantropológico de las festividades procuran no caer en la dicotomía reproducción-cuestionamiento y atienden a la articulación de sentidos de reproducción, regeneración y cambio que las mismas expresan. Desde allí atienden al reforzamiento de la legitimidad y los controles, pero también la creatividad y las resistencias al orden que las fiestas populares manifiestan o dejan entrever (Da Matta, 2002; Herrera, 2017; Segato A, 2009; Benza Solari, 2012).

En el contexto de migración y privación en que estudio, donde se reiteran sentimientos de añoranza por Bolivia, hay un aspecto de las fiestas que parece sumamente relevante: su poder evocador, el establecimiento de líneas de continuidad con una tradición, una memoria y un pasado reconstruidos selectivamente (Losada y Martín, 2009).

Diversos autores han trabajado la relación entre las fiestas y las danzas y los procesos de construcción de colectividad e identificación (Desmond, 1993; Canepa Kosch, 2001), algunos han atendido al lugar de las danzas en la transmisión generacional en poblaciones (como los grupos indígenas argentinos) donde la continuidad está desafiada (Aschieri y Citro, 2012).

La mirada sobre las fiestas y las danzas también estuvo condicionada por la potencialidad con que las mismas condensan la representación de múltiples procesos en el territorio de origen 
de la población con la que trabajo, según advertí en dos viajes recientes a Bolivia. Tanto en la zona de Cochabamba, como en Potosí y La Paz me vi de pronto en medio de sucesivas celebraciones (fiesta del Gran Poder, del Día de la madre boliviana, rituales de fertilidad de las minas, celebraciones cívicas de localidades rurales. Distintos autores sostienen que en diversos lugares de Bolivia las fiestas constituyen situaciones particularmente relevantes de la vida colectiva, adquieren sentidos rituales y funciones propiciatorias del bienestar del conjunto (Arnold-Yapita, 2005), y son ocasión para obtener estatus y poder (Poole, 1990). Otros reparan también en los procesos de sincretismo entre elementos indígenas y europeos que las festividades andinas despliegan (Podhajcer, 2015).

Las celebraciones andinas como espacios donde se despliegan tradiciones culturales diversas remite a los debates sobre procesos que algunos definen como de hibridación (Bhabha; 1998; Garcia Canclini, 1989) y otros prefieren nominar en términos de mestizaje y cruce cultural (Grusinski, 1995; De la Cadena, 2006). Estos cruces resultan evidentes en contextos de migración.

\section{FIESTAS, DANZAS E IDENTIFICACIONES ENTRE BOLIVIA Y ARGENTINA}

Para comprender el sentido de las fiestas y las danzas en situaciones de migración es necesario ubicarlas en el contexto de vida de la población boliviana en Argentina. Esta población en general se inserta en condiciones de subalternidad y sufre situaciones recurrentes de discriminación y segregación territorial (Grimson, 1999; Pizarro, 2007; Caggiano, 2014).

Se registra también el mantenimiento de relaciones sociales, económicas y políticas con Bolivia, el fortalecimiento de las asociaciones de migrantes y la tendencia a asentarse en determinados territorios con alta concentración de "paisanos" (como el barrio donde trabajo). Esta situación se vincula a procesos que alternan la invisibilización, con movimientos de afirmación de derechos y reconocimiento. Si bien estas características atraviesan en general a la población migrante procedente de Bolivia, se reconocen profundas diferencias en el modo en que las experimentan distintos grupos al interior del colectivo.

En este contexto las prácticas expresivas parecen momentos adecuados para reafirmar los vínculos de pertenencia, reeditar el lugar de origen y fortalecer la transmisión generacional (Giménez, 2008), en definitiva, para garantizar internamente la cohesión y continuidad del colectivo. Para reflexionar sobre estos aspectos resulta un antecedente interesante el trabajo de Revilla López sobre cómo impacta la transnacionalidad en la población mixteca migrante. Afirma que en situaciones de migración la música y la danza se asocian con la lucha por el poder y la negociación de la identidad. Sostiene que más que reinventar sus tradiciones, los migrantes las modernizan sin perder por ello el sentido ritual y festivo que difiere de la cultura hegemónica (Revilla López, 2006).

Las danzas son uno de los aspectos más visibles de las fiestas bolivianas. En los últimos años el fortalecimiento del nacionalismo en Bolivia se acompañó de tendencias a la revitaliza- 
ción y difusión masiva de danzas de la zona andina. ${ }^{3}$ Estas danzas son además muy practicadas por los bolivianos en el exterior. En particular los Caporales, los Tinkus, y el Salay en Argentina son muy populares entre la juventud y se muestran en reiteradas ocasiones fuera del colectivo de migrantes, por ejemplo, en desfiles patrióticos argentinos. ${ }^{4}$ En la localidad donde trabajo estos bailes se combinan con las llamadas "danzas de comunidad". ${ }^{5}$

Las fiestas y las danzas parecen adquirir múltiples funcionalidades y sentidos en contextos migratorios: construcción de sentimientos comunitarios y legitimación de lugares diferenciados al interior del colectivo, producción de imágenes hacia la nueva sociedad nacional, interpelación identitaria de las nuevas generaciones. En torno a estos tres aspectos organizo el análisis del material de campo en los siguientes puntos.

Me interesa en especial reflexionar sobre los procesos de identificación nacional que se muestran y refuerzan en las fiestas y danzas. Esto es, pensar en que medida el deseo de "seguir siendo bolivianos" que las fiestas expresan define a los espacios festivos como instancias de resistencia o distanciamiento con el proyecto asimilacionista del Estado argentino.

Mi interés en el campo educativo hace particularmente significativo atender a las relaciones generacionales que se despliegan en los bailes y las fiestas en tanto interpelan fuertemente a los jóvenes migrantes y descendientes de migrantes. Esto vincula estas prácticas a los debates que vienen sosteniéndose en torno a las segundas generaciones (Sayad 2010). En este sentido en Argentina resulta un antecedente destacado el trabajo de Natalia Gavazzo con las prácticas artísticas de los jóvenes migrantes e hijos de migrantes bolivianos y paraguayos (Gavazzo, 2014).

Pero además estos bailes (en particular los que ejecutan los jóvenes) despiertan un gran interés entre maestros y niños en escuelas donde concurren alumnos bolivianos, tal como ocurre en el barrio donde trabajo. Esto habilita que algo de "lo boliviano" se muestre en las fiestas nacionales argentinas.

3 Lo andino alude aquí al territorio de Bolivia cercano a los Andes, pero también refiere a la reproducción de ciertas prácticas asociadas a lo indígena, como el habla del quechua o el aimara, la vigencia de lazos comunitarios con los ayllus, las festividades.

4 El caporal se origina en el oriente de Bolivia. Algunos lo consideran un baile "mestizo" que expresa la mezcla de estilos. La forma coreográfica incluye movimientos repetitivos de los bailarines. El baile representa (según algunos burlonamente) la jerarquía y la autoridad (sobresale la figura del caporal portando un silbato y un látigo en alusión al capataz que dirigía a los esclavos en las plantaciones). El baile del Tinku se basa en un ritual del norte de Potosí que expresa el encuentro de contrarios y la fertilización de la tierra en homenaje a la Pachamama. El baile escenifica peleas y reconciliaciones; muestra también el valor de los grupos, la fuerza y virilidad y suele finalizar representando alianzas amorosas. El salay es una danza mas reciente que tiene su origen en Cochabamba, muy asociada a las festivales folclóricos.

5 Las danzas de comunidad se originan en zonas rurales andinas; los grupos se organizan a partir de vínculos comunitarios y familiares; están fuertemente asociadas al culto a la tierra y rituales propiciatorios de la siembra. 


\section{LAS FIESTAS Y LAS DANZAS EN EL SISTEMA EDUCATIVO}

Las fiestas escolares en Argentina están fuertemente atravesadas por el mandato nacionalista. En un país con un alto componente migratorio, desde la conformación del sistema educativo las "efemérides" buscaron la identificación con los símbolos, la exaltación de los "héroes nacionales" y el conocimiento de las "gestas patrias". A pesar de los intentos de renovación del sistema el mandato nacionalista sigue fuertemente vigente en los dispositivos generales y la cotidianidad de las escuelas.

En la versión festiva escolar de lo folclórico la figura del "gaucho de la pampa" aparece particularmente exaltada. En los últimos años, las retóricas de inclusión e interculturalidad interpelaron las formas de festejo escolar habilitando otras presencias y voces. Sin embargo, no terminaron de poner en cuestión los mandatos tradicionales.

Algunos especialistas educativos vienen reflexionando sobre el estilo "congelado" de las efemérides en el sistema educativo (Zelmanovich, 2012). Otros proponen problematizar la función moralizante y nacionalizadora de los actos escolares y sugieren dar lugar en ellos al carácter popular de los festejos (Siede, 2010).

Los debates en torno a los fines de la enseñanza de las artes en las escuelas (la danza, entre otras expresiones) plasmados en documentos del Ministerio de Educación (Cuadernos de Educación Artística, 2015) se dieron en el contexto de un sistema educativo que viene problematizándose hace al menos 30 años, en torno al mandato uniformizador con que se conformó, que procura adecuarse a las características interculturales de la población que transita las escuelas y valorizar las producciones latinoamericanas. Sin embargo, las modificaciones han sido relativas en las escuelas. Sobre todo en lo que se refiere a revisar la invisibilizacion y la ausencia, o la presencia de "los otros" en un formato estereotipado y folclorizado. Esos "otros", son por ejemplo los migrantes latinoamericanos.

\section{UN BARRIO DE FRONTERA A 2000 KM DE LA FRONTERA}

El barrio donde desarrollo mi investigación desde el año 2010 se denomina Lambertuchi; es conocido por muchos como el "barrio boliviano de Escobar". ${ }^{6}$ Se ubica $50 \mathrm{~km}$ al norte de la Ciudad de Buenos Aires y constituye un centro de producción y comercialización de productos hortícolas. De acuerdo al censo del 2010 está habitado por en una proporción significativa por migrantes e hijos de migrantes provenientes de zonas rurales de Potosí-Bolivia. ${ }^{7}$

Potosí es una de las regiones más pobres de Bolivia. Si bien la pobreza está presente en general en las biografías familiares, se registra también una importante diferenciación al interior del colectivo migrante. Esta diferenciación parece responder a marcas en origen, pero también

\footnotetext{
6 "Barrio boliviano" no es un término usado en los relevamientos censales y territoriales, corresponde a la denominación con que muchos vecinos (mayormente no bolivianos) identifican el barrio.

7 De acuerdo a datos del INDEC la presencia extranjera en el barrio ronda el 14\% siendo casi totalmente migrantes bolivianos (INDEC, Censo Nacional de población, hogares y viviendas 2010 Buenos Aires, Octubre de 2012). Hay que tener en cuenta que esta cifra triplica el porcentaje nacional de población migrante, tambien que si se incluye la población descendiente la cifra es considerablemente más alta.
} 
a trayectorias diferenciadas en destino (por ejemplo entre propietarios de terrenos y puestos de venta, medieros en las quintas, peones del mercado de frutos).

El barrio Lambertuchi se caracteriza además por la presencia de importantes organizaciones de migrantes, en particular la Colectividad Boliviana de Escobar (en adelante CBE). La misma se conforma en 1990 y reúne cerca de 1800 socios los cuales deben ser bolivianos o descendientes. La CBE sostiene actividades productivas y de comercialización vinculadas a la horticultura y los mercados de ropa. Sostiene además múltiples actividades recreativas y festivas que convocan a adultos, niños y jóvenes.

Familias y referentes de las organizaciones mantienen fuertes vínculos económicos y políticos con Bolivia (lazos con referentes políticos, contacto con parientes, viajes permanentes, emprendimientos productivos).

En Escobar y en el barrio se han producido recurrentes situaciones de violencia física y verbal hacia los migrantes entre la década del 90 y los primeros años del 2000 (secuestros, robos, frases racistas en lugares públicos). En la última década la $\mathrm{CBE}$ ha mantenido una situación de creciente cercanía con las autoridades municipales de Escobar (asistencia a actos, proyectos conjuntos, cargos de referentes en el municipio).

En el barrio hay dos escuelas primarias públicas, dos escuelas secundarias públicas y una escuela primaria privada. En estas escuelas el porcentaje de las familias bolivianas representan entre el 30 y el $40 \%$ de la matrícula (de acuerdo a los registros de las instituciones).

\section{EL TRABAJO DE CAMPO}

En los espacios familiares y comunitarios registré numerosas situaciones de interacción a lo largo de estos años. En particular considero aquí los registros de la celebración del 6 de Agosto (Día de la Independencia de Bolivia). También colaboré con iniciativas educativas de las organizaciones. En el 2019 la CBE solicitó al equipo de investigación que coordino en la universidad apoyo para producir y emitir un programa sobre educación en la radio de la organización. Este recorrido por las organizaciones me puso en contacto con numerosas familias, compartí con ellas innumerables conversaciones y situaciones de interacción cotidiana.

En las escuelas del barrio trabajé entre 2013 y 2018. Este trabajo incluyó el registro de celebraciones escolares de fiestas nacionales argentinas en las primarias y secundarias públicas.

Las situaciones se analizan principalmente desde la perspectiva de la etnografía de la educación, desarrollada en América Latina entre otros a partir de los aportes de Elsie Rockwell (2009).

Describo las festividades a partir de debates teóricos presentados en las páginas anteriores y considerando elementos del contexto que atraviesan la situación de la migración boliviana en Argentina y en particular en el barrio. El análisis de las fiestas de la Colectividad se organiza considerando tres aspectos: la construcción de sentimientos comunitarios y legitimación de lugares diferenciados al interior del colectivo, la producción de imágenes hacia la nueva sociedad 
nacional y las interpelaciones identitarias hacia las nuevas generaciones. En las fiestas escolares me detengo en las formas protocolares del festejo, los símbolos y atributos asociados con lo boliviano y lo argentino y el posicionamiento de los niños y los jóvenes.

\section{Fiestas bolivianas en Buenos Aires: "iViva mi Patria Bolivia!"}

En charlas cotidianas, en entrevistas los adultos del barrio explicitan recurrentemente las expectativas de inclusión "acá", sobre todo proyectadas hacia sus hijos: el deseo de permanecer, de romper con las biografías de pobreza y discriminación, la proyección de trayectos escolares largos y de futura inserción laboral en Argentina.

Pero también son recurrentes las alusiones al "allá". En un contexto de profundos cambios (migración, desarraigo, nuevos proyectos productivos), las familias y organizaciones de migrantes expresan reiteradamente su preocupación por la continuidad como colectivo y su deseo de que las jóvenes generaciones sigan manteniendo la referencia con Bolivia (Novaro, 2014). Esto sobre todo se traslada a los denominados "bolivianos de segunda generación" (hijos de bolivianos nacidos y criados en Argentina). Esta apuesta está presente en la expectativa de reproducción de una diversidad de prácticas (participación en los mercados de venta, viajes a Bolivia) y en forma muy visible en la participación en las fiestas y las danzas bolivianas.

La Colectividad afirma entre sus objetivos el homenaje a "nuestra patria Bolivia...y las manifestaciones culturales propias de nuestras raíces bolivianas" (Página oficial de la Colectividad Boliviana de Escobar, abril de 2017). Las fiestas corresponden a las fechas patrias nacionales y también a festejos regionales (básicamente el día de Potosí) y otros festejos como el carnaval, las fiestas patronales, etc. Me centro aquí en el festejo del 6 de agosto, día de la Independencia de Bolivia. ${ }^{8}$

Varias semanas antes de la fiesta la dinámica de la Colectividad gira en torno a la celebración: los organizadores suelen viajar a Bolivia a comprar adornos para los salones y las calles del barrio, buscar instrumentos musicales y trajes de danza. Se refuerza también el contacto con autoridades locales buscando garantizar la presencia de representantes de la embajada y el consulado de Bolivia, de otras colectividades de migrantes, de las autoridades del municipio de Escobar. Los grupos de danza terminan de definir su conformación, que en general se realiza entre bolivianos o descendientes; acuerdan el modo de desfilar y bailar, arreglan sus vestimentas, practican los pasos y la coordinación conjunta en terrenos de la CBE.

La fiesta del 6 de agosto tiene año a año una estructura similar. La siguiente descripción se centra en la celebración del 2019, pero se apoya en situaciones registradas desde el año 2012.

E1 3 de agosto de 2019, junto con otros integrantes del equipo de investigación que coordino, asistí a la fiesta en calidad de "invitada especial" por mi participación en el programa de radio de la CBE. Unos días antes la Secretaria de Cultura de la CBE me solicitó además que

$8 \quad$ En muchas de estas fiestas también se ponen en evidencia las referencias de identificación étnica de la población. Este aspecto resulta sumamente significativo, aunque por razones de espacio no profundizo en ello aquí. 
integrara el jurado del concurso de danza. Me dijo entonces: "En el jurado tiene que haber tres de la Colectividad y tres neutrales".

Llegamos a los terrenos de la Colectividad, las calles de entrada están adornadas con banderines con los colores de la bandera boliviana. En el predio donde se hará el acto protocolar y el desfile han puesto un palco, gradas y vallas. LLegan las autoridades de la CBE y se ubican en el palco. Otros años he registrado tensiones y conflictos por quien accede al palco y a las gradas principales que siempre están repletas. Muchos tienen escarapelas bolivianas en el pecho, algunos también portan escarapelas argentinas más pequeñas encima. Se izan la bandera de Bolivia, la de Argentina y la wiphala. ${ }^{9}$ Al lado del escenario se coloca una banda de música que tocará los himnos argentino y boliviano, la marcha de Malvinas y tonos marciales. Hablan las autoridades del municipio, de la CBE, del consulado. Se reiteran expresiones como "iViva Bolivia, viva Argentina, viva Escobar!” “'Mar para Bolivia, Malvinas para Argentina!”, "Escobar es un pedazo de Bolivia en Argentina".

El presidente de la CBE agradece la colaboración del municipio y afirma que la Colectividad "trabaja para toda la comunidad de Escobar". El cónsul enuncia su discurso en parte en español, en parte en quechua, invoca a la "Patria Grande" que imaginó Bolivar y la unión de los países latinoamericanos.

Luego del discurso comienza el desfile. Como todos los años, lo encabezan las autoridades, seguidas por los trabajadores de las ferias de frutos y de ropa, las colectividades vecinas, numerosos grupos organizados por la región de origen en Bolivia. Suelen portar estandartes de los cantones y ayllus de origen, la wiphala, la bandera boliviana y la argentina.

Puestos instalados a unos metros del escenario venden productos para cocinar comida reconocida como boliviana (chuño, quínoa, porotos, locoto).

Vamos al comedor donde se sirve un almuerzo. En años anteriores he registrado peleas por quien accede o no al salón. Mientras comemos de fondo repiten muchas veces la canción "Viva mi patria Bolivia". ${ }^{10}$

Fuera del salón, frente al palco se desarrolla a la tarde el concurso de danzas bolivianas. Otros años incluyó también bailes identificados con el folclore argentino.

Me siento en la mesa frente al palco junto con las princesas de la belleza y el secretario de cultura del año anterior que también integran el jurado. Converso con una de las princesas, joven argentina hija de padres bolivianos ${ }^{11}$ : "Bailo desde que tenía dos años. Mis abuelos tenían un grupo, fue de familia ya, entre tíos, primos..., no era fraternidad, se llamaba tinkus de Otavi de donde era mi mama, bailábamos a devoción de la virgen de Urkupiña. Cuando falleció mi abuela dejamos de bailar, por duelo...y después de tanto tiempo me dieron ganas de volver a tener las costumbres no perderlas... y fui con mis primas a la fraternidad de salay... Me gustaría mostrar en la escuela, estaría lindo que se vaya reconociendo".

Me dan dos planillas para evaluar. En una deben puntuarse los "grupos de comunidad", en otro los "grupos folclóricos". Para ambos tipos de baile los criterios de evaluación son los mismos: baile, vestimenta y coreografía. El concurso durará varias horas. Las gradas están repletas y hay cada vez más gente. La diferencia generacional es clara entre los dos tipos de danzas. Los grupos de comunidad son ejecutados en general por adultos mayores, incluyendo en ocasiones algunos niños. Hacen sus bailes en ronda, los hombres en el centro tocando instrumentos de viento, frecuentemente bandas de sikuris, parejas de hombres y mujeres o mujeres solas del brazo dan vueltas en círculo alrededor en movimientos similares. Los hombres portan sombreros adornados o guirnaldas con flores, panes colgados en el cuello, ponchos en ocasiones muy bordados; las mujeres visten con "ropa cotidiana" o "polleras de cholas" y aguallos. Las danzas folclóricas, son mayormente bailadas por jóvenes, requieren una gran resistencia y en algunos casos incluyen la ejecución de pasos acrobáticos sobre todo de los varones. Los trajes son muy producidos, con brillos, lentejuelas (en el caporal y

$9 \quad$ bandera de los pueblos originarios, reconocida como símbolo del Estado Boliviano en el año 2008.

10 "Viva mi Patria Bolivia, una gran nación, por ella doy mi vida, también mi corazón. Esta canción que yo canto, la brindo con amor, a mi patria Bolivia, que quiero con pasión. La llevo en mi corazón, y le doy mi inspiración, quiera a mi patria Bolivia, como la quiero yo".

11 Esta charla continuó días después en una entrevista para la radio. 
el salay) y telas tradicionales en el tinkus.

Durante el desfile los locutores reiteran frases tales como "que no se pierda la cultura", "esto es lo más lindo que podemos dejar a nuestros hijos", "ellos llevan a Bolivia en la sangre".

Los asistentes sacan muchas fotos y alientan a sus familiares que concursan. Otros años, cuando pude observar espacios menos formales del festejo, advertí que varios grupos que participan en la competencia luego de mostrar su número siguen bailando al costado o atrás del escenario en rondas y filas. He registrado que estos bailes se prolongan varias horas, convocan grupos de distintas edades. Muchos consumen alcohol y tiran bebida al piso invocando a la Pachamama.

El concurso de danza termina con una descarga de fuegos artificiales y la entrega de los premios (generalmente dinero). Continúa luego un baile "familiar" con conjuntos musicales de Bolivia. Según me han comentado este baile convoca mayormente a los jóvenes, "los grandes ya están agotados". (Registro 3 de Agosto de 2019)

Hacia dentro del colectivo migrante el acto enuncia aspectos unificadores sostenidos en la referencia común a un territorio habitado en el pasado. Se reitera la invocación a "todos los bolivianos". Pero la fiesta muestra simultáneamente frases e imágenes que legitiman la jerarquía y la autoridad; esto resulta claro en las situaciones y dispositivos más protocolares del festejo. Es evidente también que el acto formal coexiste con expresiones en sus márgenes que lo acercan a lo que imaginamos como un festejo popular, donde lo planificado es desbordado y tienen lugar formas de cohesión menos instituidas.

Para pensar en los sentidos de la fiesta hacia dentro del colectivo migrante decía al principio que resulta sugerente (a pesar de hacerse en un contexto tan distinto al de los festejos carnavalescos medievales) la caracterización de Bajtin de la cultura cómica popular del carnaval y su tendencia a oponerla a las fiestas oficiales. La oposición entre "lo serio y lo grotesco" no parece fácilmente aplicable a la situación descrita y nos plantea la pregunta acerca de si el 6 de agosto en Escobar puede caracterizarse como un festejo popular. En principio no dudaría en responder que este festejo tiene muchos elementos de fiesta popular, sin dejar de ser, en muchos sentidos, una fiesta oficial organizada y regulada por una institución civil con fuertes atravesamientos por la lógica estatal y de consagración de la jerarquía. E1 6 de agosto lo "oficial" y "lo popular" parecen coincidir en momentos y lugares diferenciados de la misma fiesta.

Se registra la forma estatal-oficial del festejo en las marchas militares, los discursos de los funcionarios, las banderas, los himnos. En la expresión oficial del festejo la legitimación de la diferenciación interna se hace evidente en el lugar destacado de las autoridades y los invitados especiales, las disputas por el palco, los desfiles, las competencias, las premiaciones, las gradas y las vallas que separan autoridades, ejecutantes, y observadores.

Se registran también formas y estilos que parecieran alejarse de lo estatal: bailes paralelos a la competencia, circulación de bebida, prácticas rituales andinas, culto a la Pachamama.

La fiesta podría ser pensada como un acto oficial de la Colectividad (recordemos que se trata de una organización con poder pero que nuclea un colectivo que se incluye en forma subordinada en el nuevo contexto nacional) que toma elementos de fiesta popular. Esta coexistencia de lo oficial y lo popular pareciera permitir que la fiesta exprese a la vez sentidos de diferenciación y de igualdad. 
La fiesta da mensajes hacia dentro y hacia fuera de la Colectividad. Se alternan situaciones donde Bolivia parece la referencia excluyente, con otras donde se expresa la situación binacional. Al tiempo que el acto refuerza la pertenencia a Bolivia, no pierde oportunidad de dar señales a los argentinos: la Colectividad trabaja para el barrio, se articula con autoridades municipales, explicita el apoyo al reclamo argentino en Malvinas. Creo que en este sentido debo significar incluso el hecho de haber sido convocada como "neutral" a integrar el jurado del concurso de danzas bolivianas.

Los bailes expresan también esto. Mientras los bailes de comunidad parecen expresión de una continuidad añorada, ¿qué manifiestan los bailes folclóricos de los jóvenes? Hacia fuera de la colectividad el mensaje de Tinkus, Caporales y Salay parece ser de visibilizacion. En la situación de pobreza y discriminación que suele caracterizar a los migrantes provenientes de Bolivia el despliegue de destrezas corporales, los colores llamativos, la masividad de las danzas podría interpretarse como una lucha por el derecho a la propia imagen y reconocimiento. (Novaro, 2018). Características de las danzas como la representación de la desigualdad y la opresión (en el caporal) y de la confrontación y el reencuentro (en el tinkus) parecen además corresponder con aspectos estructurales de las relaciones sociales internas de la Colectividad y también del modo de encontrarse y desencontrarse con el afuera.

Las fiestas nacionales bolivianas muestran a un colectivo que afirma su intención de seguir viviendo en Argentina. Seguir habitando un lugar coexiste con el deseo de continuar vinculada a la nación de origen. Este deseo de permanecer en un lugar y seguir perteneciendo a otro, se expresa en las apuestas identitarias trasladadas a las jóvenes generaciones, bolivianos también ellos, fuera de Bolivia.

Me pregunto considerando esto último por las formas de inclusión de las distintas generaciones en las fiestas, esto es, si las distintas generaciones viven la misma fiesta. En el caso de los descendientes, es necesario considerar que para muchos de ellos la memoria de Bolivia supone la invocación a un espacio desconocido, pero de fuerte referencia para los adultos. Las familias son sin duda fuertes sostenes para posibilitar su presencia. En todos los festejos se observa que, acompañados de sus familiares, los niños y jóvenes se incorporan en los desfiles con vestimentas, instrumentos y coreografías andinas, son fotografiados permanentemente, agitan banderas, comen comida boliviana, juegan al futbol con la camiseta de la selección de este país, exhiben en su propio cuerpo, sus referencias de identidad (¿゚ las que sus padres esperan que exhiban?). La misma participación del evento parece constituir de alguna manera, una señal de pertenencia al colectivo.

La masividad de la participación de los jóvenes en las danzas folclóricas bolivianas es significativa. También los relatos registrados acerca de que la integración de las fraternidades de danza son decisiones que tomaron los jóvenes autónomamente, pero muchas veces asociadas al recuerdo de experiencias de participación en bailes familiares cuando eran niños (como en el caso de la princesa de la belleza).

Esta presencia de todas formas debe continuar siendo analizada. Los sentidos de identificación con "lo boliviano" que esperan los adultos, no parece ser reproducida en términos idénticos en los jóvenes. 
Vimos que ciertos ritmos andinos (caporal, tinkus, salay) son muy populares en ellos, otros solo son bailados por los adultos mayores. La diferencia generacional en la integración de las danzas de comunidad y las danzas folklóricas es significativa. La conformación de los grupos de danza comunitaria expresa referencias territoriales y a grupos de parientes; los adultos afirman integrarlos buscando dar continuidad a las tradiciones. Los grupos de danzas llamadas folclóricas se sostienen en la intención de continuidad con la tradición de los padres, pero sobre todo en relaciones de sociabilidad y de empatía intrageneracionales. Incluso he registrado entre los jóvenes la creciente presencia de consumos culturales que nada tienen que ver ni con el folclore argentino ni con el boliviano (como el pop coreano), pero que advertí muy extendidos en los jóvenes en Bolivia durante mis estancias en ese país.

Es importante no perder de vista que todo esto se da en un contexto donde permanentemente se discute (con más o menos sutileza) la nacionalidad única atribuida por el Estado, se gestiona la doble nacionalidad de algunos niños y también se apuesta a la radicación en un territorio donde para muchos migrantes siguen en cuestión los derechos de permanencia.

\section{FIESTAS ESCOLARES ARGENTINAS EN EL "BARRIO BOLIVIANO"}

Las familias bolivianas en Buenos Aires asocian la escuela a un espacio del Estado nacional argentino con el cual en ocasiones sienten una gran distancia; sobre esta cuestión me he detenido en diversos trabajos previos (Novaro,2014; 2018). No obstante se registran intentos de acercamiento en muchos momentos de la vida escolar y también en las fiestas. La presencia en los actos escolares es una cuestión valorada en las organizaciones: los representantes de la Colectividad asisten cuando son convocados, donan banderas bolivianas y tortas.

He registrado que la escuela permanece bastante alejada de las festividades bolivianas, más allá de la presencia de alguna autoridad cuando la escuela es especialmente convocada. En los relatos de los docentes las fiestas bolivianas se conciben como "de ellos", se habla de "sus actos" y "sus celebraciones"; registré también frecuentes críticas a los desbordes de bebida y comida que se asociaban a estas fiesta.

La escuela primaria pública más cercana a los terrenos de la Colectividad es conocida por muchos como "la escuela de los bolivianos", si bien se registran recurrentes intentos de los docentes por evitar esa asociación.

En los actos escolares del año 2010 coincidiendo con los festejos del bicentenario de la revolución de mayo se entonaron el himno argentino y el boliviano y se comentó cómo se enlazan las historias de ambas naciones. La maestra de plástica pintó con sus alumnos un mural en el frente con motivos asociados a Bolivia y Argentina. Un tiempo después cambió la dirección, el mural fue blanqueado y el himno boliviano dejó de tocarse en los actos. En las charlas con la nueva directora de la primaria esta me comentó con orgullo "en esta escuela todos los años los chicos van a Rosario (ciudad del interior del país con un enorme monumento a la bandera) a jurar lealtad a la bandera (argentina) que es su bandera”.

En el colegio secundario vecino a esta escuela primaria registré sostenidos intentos de la dirección por aproximarse a las familias bolivianas y a la Colectividad. También registré limi- 
taciones de la institución para concretar estas intenciones (sobresaturación de tareas, discontinuidad de planes y proyectos, ausencia de personal). En el 2017 y el 2018 registré interesantes situaciones que dan cuenta de la apertura y clausura de espacios para otras presencias en los actos escolares.

La directora nos comentó días previos al festejo del acto del 12 de octubre de 2017: “...ahora el festejo lo organizan los alumnos... unas chicas me vinieron a preguntar si podían bailar caporales con bóxer, porque viste que los trajes son cortísimos, les dije que se pongan una calza". El día del acto las chicas que bailaban pidieron permiso a la directora para que se sumara un joven bailarín que no era alumno de la escuela. La directora se negó diciendo que debían haber pedido permiso antes. Cuando el acto comenzó la directora pidió que se ordenaran y se formaran dividiendo claramente lo que definió como la parte protocolar (el himno y los primeros discursos de los chicos) de la segunda parte: "después pueden ponerse cómodos y disfrutar del acto". Al retirarse las banderas las actividades fueron organizadas por una estudiante de los primeros años. Hizo un gran crucigrama con la palabra DIVERSIDAD, continuó luego refiriéndose al significado de los colores de la Whipala. (Registro del acto del 12 de octubre, 2017).

E1 9 de Julio del 2018 (festejo del día de la independencia Argentina) la fiesta se hizo en la plaza ubicada frente a la escuela. Los jóvenes de la secundaria dieron una vuelta a la plaza portando una enorme bandera argentina. Las palabras de inicio de un docente aludieron a las relaciones históricas de Argentina y Bolivia. Se desplegó una dinámica muy interesante: mientras las autoridades escolares organizaban a los chicos más pequeños para ejecutar danzas típicas del folclore argentino, un grupo de jóvenes, por su propia iniciativa, practicaba bailes caporales y tinkus dentro de la escuela coordinados por un joven integrante de fraternidades, y luego bailaron en la plaza. (Registro en colaboración Novaro- Diez, acto del 9 de julio de 2018)

La otra escuela se muestra más desmarcada de las referencias a lo boliviano. Es la más demanda por las familias del barrio.

En la escuela primaria la fiesta que más se celebra según varios docentes es el día de la tradición en noviembre. ${ }^{12}$ En estos festejos abunda el despliegue de ritmos identificados con el folclore argentino "nuestros bailes". La fiesta de acuerdo a expresiones que las docentes suelen reiterar en los discursos de apertura se propone mostrar como "Nuestra comunidad se mantuvo siempre ligada a las tradiciones argentinas". Ocasionalmente se bailan también caporales o tinkus presentados como "danzas típicas bolivianas". Algún año se da más lugar a esto y al siguiente queda bastante minimizado. La presencia de las familias también es variable; suelen asistir sobre todo aquellos que tienen hijos pequeños, ayudan a vestir a sus hijos, luego en general están sentados o parados frente al escenario mirando el acto y sacando fotos.

En 2017 registré el festejo del 25 de Mayo en la escuela secundaria que articula con esta primaria.

El festejo se realizó en el patio sobre un escenario con globos, guirnaldas, escarapelas y banderas celestes y blancas, una imagen del cabildo de Buenos Aires y "Viva la patria" con letras doradas. No escuché en las cuatro horas ninguna mención a otra nación que no sea la Argentina, tampoco vi ninguna bandera ni símbolo que no fuera argentino. Abundó el revoleo de pañuelos celestes y blancos, las chicas vestidas de paisanas, los chicos de gauchos bailando zambas y chacareras. Los jóvenes daban sus notas de color escapándose del acto, mirándolo de a ratos, burlando a los actores y la escenografía, abrazándose, besándose y sacándose fotos permanentemente, escuchando otros ritmos en sus celulares. Muchos miraban con distancia el despliegue folclórico y tradicionalista, pero alentaban con aplausos, vítores y gritos la actuación de sus compañeros (registro acto escolar del 25/05/17)

12 El día de la tradición conmemora el nacimiento del poeta argentino José Hernández que a fines del siglo XIX escribió "El gaucho Marín Fierro" a partir del cual el gaucho (figura característica de las pampas argentinas) se instaló como personaje emblemático del folclore argentino. 
Los registros muestran la habilitación para el despliegue, aunque sea en un formato folklorizado, de estéticas que hasta hace algunos años era difícil imaginar en las escuelas. No obstante, lo nacional argentino sigue teniendo una gran centralidad en los actos. Predominan claramente los símbolos y bailes "argentinos", "criollos", "nuestros" que se espera interpelen tanto a los niños y jóvenes argentinos como a los de otras nacionalidades. Las “otras” expresiones y referencias se presentan en forma esporádica, fragmentaria, dependiendo de las autoridades de turno. Resulta además significativo que la escuela defina como danzas típicas bolivianas (caporales, tinkus) aquellas que en el contexto de la colectividad son asociadas a los jóvenes y se diferencian de "las de comunidad".

Llama también la atención la búsqueda de otras formas de festejo, el protagonismo que parece habérseles dado a los jóvenes. Desde la asunción de este protagonismo en ocasiones los jóvenes reproducen formas escolares tradicionales (los crucigramas, los discursos); pero también rompen relativamente con la lógica de lo instituido y lo controlable (como en el acto del 2018 cuando se apropian de la preparación y despliegue de danzas en una de las escuelas secundarias). El mayor o menor protagonismo de los jóvenes es tema de tensión y negociación constante con las autoridades. Nuevas presencias se decodifican también como amenazas: los cuerpos potencialmente expuestos, el ingreso de los externos a la escuela. La institución afirma dar lugar a lo "no protocolar", pero a condición de tener garantizado el control de lo que podría escapar a lo planificado.

Los jóvenes, además de asumir y reproducir la lógica y estilos escolares, se ubican en una posición que parece tanto condicionada por las referencias de origen de sus familias, como por los estilos y estéticas propias. En la tensión entre las interpelaciones a lo boliviano y lo argentino, muchos de ellos eligen una posición corrida de ambos, al menos en la escuela.

\section{CONCLUSIONES}

El sentido de la fiesta y de las danzas en contextos comunitarios surge en su vinculación con otros ámbitos de prácticas y con la historia y los dilemas presentes del colectivo. Es en esta vinculación que advertimos la relevancia que para los migrantes adquiere la visualización de su pertenencia y la inscripción de la nación en el cuerpo que la fiesta y las danzas propician. También la intención de representar su condición binacional.

Los registros dan cuenta de que las fiestas y las danzas, junto con muchas otras prácticas, se han constituido en una forma de escenificar y hacer visible la pertenencia al colectivo boliviano, de seguir siendo bolivianos fuera de Bolivia. También evidencian la intención de poner en cuestión el estigma de sumisión que atraviesa esta población y la proyección de permanencia e inclusión en el nuevo territorio.

Estas prácticas tienen importantes significados "hacia adentro". Muestran la integración pero también la fragmentación, la competencia y la jerarquía. Las danzas como el caporal y el tinkus, las selecciones y premiaciones parecen en consonancia con la estratificación, la confrontación y también los intentos de integración que caracterizan las relaciones al interior de la colectividad y la vinculación de esta con la nueva sociedad nacional. 
El sentido de participar en la fiesta y bailar las danzas bolivianas se comprende poniendo estas prácticas en relación con el contexto general, pero también con las múltiples escenas locales: el lugar donde se baila (terrenos de la Colectividad), y el momento (fiesta patria boliviana), las palabras que reiteran la presencia de Bolivia, los símbolos, los vestidos, las comidas.

Me he preguntado qué sucede cuando algunas de estas mismas danzas se bailan en la escuela, en otros espacios y tiempos y acompañadas de otras palabras.

La continuidad de los aspectos representados y exaltados de lo boliviano y el despliegue autorizado de símbolos de lo nacional argentino en los espacios comunitarios se diferencia de la fluctuación entre la visibilización y la invisibilizacion de lo boliviano en las imágenes y relatos escolares.

En general se advierte en las escuelas, la limitación de estéticas y practicas asociadas a los festejos populares, la permanencia de un estilo protocolar fuertemente institucionalizado y el miedo a los desbordes vinculados a los cuerpos, la dilución de las fronteras entre el adentro y el afuera de la institución. Habría que considerar que una dosis de pérdida del control tal vez es una condición necesaria para que algo de lo popular traspase el portón de la escuela. En ese sentido es importante recuperar escenas donde los jóvenes irrumpen el control adulto y donde esa irrupción, lejos del desborde, habilita expresiones creativas y la visualización de pertenencias que el sistema ha ocultado o desvalorizado.

La presencia de "lo boliviano" habilitado por la institución en los actos escolares se aproxima mucho a una forma patrimonializada de la cultura. En la escuela hoy el "otro nacional" se presenta a través de sus coloridos, vestimentas, ritmos. Esto no es un detalle menor considerando los tradicionales mandatos nacionalistas, las históricas presencias y ausencias en el sistema. Pero también es cierto que esta forma de despliegue de "lo boliviano autorizado" no se corresponde con un posicionamiento claro de reconocimiento. Varía de acuerdo a las voluntades de turno. En la escuela lo que en general no se muestra es justamente el contexto comunitario de significación de las prácticas.

A pesar de los buenos discursos y seguramente de las mejores intenciones de muchos docentes se registra la dificultad para hacer visible y trabajar con el carácter binacional y las experiencias transnacionales de las familias y los chicos que transitan la escuela y del mismo barrio donde se inserta. También para dar legitimidad a las formas culturales de los jóvenes que frecuentemente no parecen corresponder ni con lo tradicional argentino ni con lo tradicional boliviano.

La dinámica generacional es un aspecto que hemos considerado centralmente en el contrapunto entre las fiestas comunitarias y escolares. La presencia de muchas generaciones que la fiesta y los bailes de la Colectividad convocan, choca con el estilo escolar tradicional, donde por lo general los docentes organizan, los jóvenes y niños ejecutan y los padres miran. En la fiesta y el baile comunitario evidentemente la asociación con Bolivia se refuerza por la presencia activa y protagónica de adultos que los "descendientes" asocian a ese territorio. La continuidad en la transmisión generacional se realiza, aunque con límites (clara expresión de lo cual es la discontinuidad en la transmisión de las formas tradicionales de danzar). 
La forma escolar de enseñar que organiza las actividades por edad y en tiempos y espacios determinados pone límites a la posibilidad de pensar a adultos, niños y jóvenes expresándose en simultaneidad. Se pierden así muchas posibilidades, sobre todo la de mostrar que muchas de las actuales expresiones del "acá", tienen fuertes marcas del "allá".

\section{Biblografía}

Arnold, Denise y Yapita, Juan. 2005. El rincón de las cabezas. Luchas textuales, educación y tierras en los Andes. La Paz: ILCA, Universidad Mayor de San Andrés.

Bhabha, Homi. 1998. El Lugar de la Cultura. Buenos Aires: Manantial.

Bajtin, Mijail. 2003. La cultura popular en la Edad Media y en el Renacimiento. El contexto de François Rabelais. Madrid: Alianza.

Caggiano, Sergio. 2014. "Riesgos del devenir indígena en la migración desde Bolivia a Buenos Aires: Identidad, etnicidad y desigualdad”. Amérique Latine Histoire \& Mémoire. Les Cabiers ALHIM 27/2014. Disponible en http://alhim.revues.org/4957

Canepa Koosh. Gisela. 2001. Identidades representadas. Performance, experiencia y memoria en Los Andes. Pontificia Universidad Católica del Perú.

Citro, Silvia y Aschieri, Patricia (coord.). 2012. Cuerpos en movimiento. Antropología de y desde las danzas. Buenos Aires: Biblos.

Da Matta, Roberto.2002. Carnavales, malandros y héroes. Hacia una sociología del dilema brasileño. México: Fondo de Cultura Económica.

De la Cadena, Marisol. 2006. “'Son los mestizos híbridos? Las políticas conceptuales de las identidades andinas." Universitas humanistica (61): 51-84.

Desmond, Jane. 1993. "Embodying difference: issues in dance and cultural studies." Cult. Critique (26): 33-63.

García Canclini, Néstor. 1989. Culturas hibridas. Estrategias para entrar y salir de la modernidad. México: Grijalbo.

Gavazzo, Natalia. 2014. "La generación de los hijos: identificaciones y participación de los descendientes de bolivianos y paraguayos en Buenos Aires”. Sociedad E' Equidad (6): 58-87.

Giménez, Gilberto. 2008. "Cultura, identidad y memoria. Materiales para una sociología de los procesos culturales en las franjas fronterizas". Frontera Norte 21 (41): 7-32

Grimson, Alejandro. 1999. Relatos de la diferencia y la igualdad. Buenos Aires: EUDEBA

Gruzinski, Serge. 1995. La guerra de las imágenes. De Cristóbal Colon a Blade Runner (14922019). México, Fondo de Cultura Económica.

Haesbaert, Rogerio. 2013. "Del mito de la desterritorialización a la multiterritorialidad“. Cultura y representaciones sociales 8 (15): 9-42.

Herrera Nicolás. 2017. "La fiesta como objeto y contexto de investigación en el campo de los estudios migratorios y el campo historiográfico de la Argentina”. Pp 28-48 en Ceremoniales festivos. Argentina, Brasil, Colombia y México por Gonzales Pérez. Colombia: Intercultura.

Levitt, Peggy y Glick Schiller, Nina. 2004. "Perspectivas internacionales sobre migración: conceptuar la simultaneidad." Migración y Desarrollo (3): 60-91.

Losada, Flora y Martin Alicia. 2009. "Fiesta y ritual". Cuadernos de la Universidad Nacional de Jujuy (36): 13-21.

Novaro, Gabriela. 2018. "Dances in migratory, community and school contexts: identity marks and folklorised presences". Ethnography and Education 13: 340-358 
Novaro, Gabriela. 2014. "Procesos de identificación nacional en población migrante: continuidades y quiebres en las relaciones intergeneracionales". Revista de Antropología Social, Universidad Complutense de Madrid 23: 157 - 179.

Novaro, Gabriela y Diez, M Laura. 2011. “¿Una inclusión silenciosa o las sutiles formas de la discriminación? Reflexiones a propósito de la escolarización de chicos bolivianos" Pp 37-57 en Discriminaciones étnicas y nacionales - Un diagnóstico participativo por Courtis, Corina y Pacecca, María Inés (comps). Buenos Aires: Editores del Puerto.

Pizarro, Cynthia. 2007. "Inmigración y discriminación en el lugar de trabajo. El caso del mercado frutihortícola de la colectividad boliviana de Escobar". Estudios Migratorios Latinoamericanos 21(63): 211-244.

Poole, Deborah. 1990. "Accommodation and resistance in Andean ritual dance". Drama Rev. 34 (2): 98- 126.

Podhajcer Adil. 2015. "Sembrando un cuerpo nuevo: Performance e interconexión en prácticas musicales andinas de Buenos Aires”. Revista Musical Chilena, 69 (223): 47-65.

Revilla López, Ulises. 2006. "La chilena mixteca transnacional". Pp 237-281 en San Juan Mixtepec. Una comunidad transnacional ante el poder clasificador y filtrador de las fronteras por Besserer, F. \& Kearney, M. (Eds.). México: Casa Juan Pablos, Universidad de California Riverside, Universidad Autónoma Metropolitana, Departamento de Antropología.

Ribera Cusicanqui, Silvia. 2010. Ch’ixinakax Utxiwa: Una reflexión sobre prácticas y discursos descolonizadores. Buenos Aires: Retazos, Tinta Limón.

Sayad, Abdelmalek. 1998/2010. La doble ausencia. De las ilusiones del emigrado a los padecimientos del inmigrado. España: Anthropos.

Segato, Rita. 2007. La nación y sus otros: raza, etnicidad y diversidad religiosa en tiempos de politicas de la identidad. Buenos Aires: Prometeo.

Siede Isabelino. 2010. Ciencias Sociales en la escuela. Criterios y propuestas para la enseñanza. Buenos Aires: Aique Educación.

Zelmanovich, Perla. 2012. Efemérides, entre el mito y la historia. Buenos Aires: Paidós.

\title{
National Festivities and Dances in Migrant Organizations AND SCHOOLS IN BUENOS AIRES, ARGENTINA. CONTINUITIES AND DISCONTINUITIES IN THE GENERATIONAL TRANSMISSION
}

\begin{abstract}
The following reflections on feasts and dances is part of an ongoing research on migration and education of Bolivian migrants in Buenos Aires, Argentina. Especial attention is given to the inter-generational transmission of identity markers within family, school and community contexts. Feasts bring together different generations, provoking tensions between "continuing to be" (Bolivian) and "continuing to live" (in Argentina). The article examines these tensions in a neighbourhood of the Buenos Aires province with a high number of Bolivian migrants and descendants, contrasting the performance of Bolivian dances in community celebrations with those at school feasts. The latter are marked by strong nationalist tendencies that interferes with the transnational condition of children and young people.
\end{abstract}

Keywords: festivities, dances, migrant organizations, schools, national identification, genera- 
tional transmission

Data recibido: 2019-09-01

Data aceptado: 2020-05-30 